\title{
'Stick to it' - Exercise Programmed Adherence as the Main Deter- minant of Successful Weight Loss Interventions
}

\author{
Santiago Tavares Paes* and Renato Marques Bianchini \\ Faculty of Physical Education and Sports, Federal University of Juiz de Fora, Brazil
}

*Corresponding author: Santiago Tavares Paes, Faculty of Physical Education and Sports, Federal University of Juiz de Fora, Antonio Rufino St, n206 apt 202, Brazil, Tel: 553288368085, E-mail: santtpaes@hotmail.com

\begin{abstract}
The regular practice of physical exercise can improve the functioning of energetic systems, increasing metabolic efficiency, which reduces the progression of the pathological effects of obesity. The increase in energy expenditure secondary to physical exercise occurs by stimulating the metabolic reactions and the enhancement of energy substrate use by active exercised muscles. There are many metabolic factors activated by exercise. This activation can occur acutely and chronically, increasing muscle mass and oxidative rates of fat acids, and improving of hormonal signaling, the main metabolic aspects associated to enhancements in the efficiency of body energy systems and all biochemical reactions. However, it's necessary that exercise practice is performed daily. Independently of type, intensity or frequency of physical exercise, the major component that leads changes of behavior and lifestyle, is adherence to regular practice. Thus, it is necessary that health professionals focus on this aspect and create strategies for maintenance of exercise by obese individuals. Furthermore, it is necessary that psychological aspects are incorporated somehow into the physical training program for obese people.
\end{abstract}

\section{Keywords}

Obesity, Exercise, Metabolism, Weight loss, Lifestyle, Fat loss, Obesity treatment, Exercise psychology

\section{Introduction}

The etiology of obesity seems to be related to a number of factors, such as sedentary lifestyle, irregular eating habits, genetic polymorphisms, hormonal signaling dysfunction, systemic inflammation, increased intestinal absorptive capacity, among other $[1,2]$.

The regular physical exercise practice promotes physiological adaptations that enhance the metabolic functioning of the human body, increase the usage of energy substrates, and improve the molecular function of metabolic systems [2]. Physical exercise has been used as an important tool in the prevention and treatment of obesity by positively alter body composition, metabolic activity and attenuating the comorbidities associated with excess weight. An inverse association has been demonstrated between physical exercise level and development of obesity [1].

Physical exercise improves the functioning of energetic systems, increasing metabolic efficiency, which reduces the progression of the pathological effects of obesity. The recurrent practice promotes the improvement of hormone responsiveness both central as peripheral, enzymatic activity, vasodilatory capacity, myocardial perfusion, cardiac contractility, appetite regulation, satiety and hunger, release of anti-inflammatory adipokines and also myokines, body composition (increased muscle mass and reduced fat mass), adrenergic activity and lipolysis, mitochondrial density, cellular oxidative capacity, and many other factors [1-3].

The consequence of this are lower triglycerides rates, decreased dyslipidemia, atherosclerosis, fatty liver, hypertension, insulin resistance, type 2 diabetes mellitus, sympathetic nerve activity, among several other cardiometabolic risk factors directly associated to mortality [1].

However, it is important to note that the magnitude of physiological benefits of training is closely associated with the type of physical exercise (i.e. aerobic or resistance training), weekly frequency (number of practice

Citation: Paes ST, Bianchini RM (2018) 'Stick to it' - Exercise Programmed Adherence as the Main Determinant of Successful Weight Loss Interventions. Int J Sports Exerc Med 4:101. doi.org/10.23937/24695718/1510101

Accepted: August 02, 2018; Published: August 04, 2018

Copyright: (c) 2018 Paes ST, et al. This is an open-access article distributed under the terms of the Creative Commons Attribution License, which permits unrestricted use, distribution, and reproduction in any medium, provided the original author and source are credited. 
days), duration of activity (minutes or hours), intensity of training loads (heart beats per minute, oxygen uptake volume, maximal voluntary repetitions, velocity, etc.) and biological individuality $[2,4]$.

By modulating these variables related to physical exercise, the individual can improve the functioning of energy systems and increase energy expenditure of the activity in both acute and chronic state [5].

For example, a physical training that the objective is weight loss and improvement of body composition of obese individuals should contain at least: 150-210 minutes of aerobic exercise of moderate intensity (3-5 times per week; $40 \%-60 \%$ of heart rate reserve, or about $4-6$ metabolic equivalents), 60-120 minutes of resistance training, hypertrophic type is preferable (2-3 times per week; i.e. Start with 1 set of $10-15$ repetitions at moderate weight; Progress to 2 sets of 10-15 repetitions; Progress to 3 sets of 8 repetitions at heavier weight), flexibility exercises should be added in separate sessions in order to avoid muscle and joint injuries [4].

The obesity can also increase the risk of orthopedic injuries. This is due to increased load in joints promoted by excess weight and the inflammatory disease condition [6].

It is necessary to conduct an orthopedic assessment of the obese individuals before starting an exercise program, which the main reason is the increased energy expenditure. Thus, the prescription and choice of type can be started with activities that will promote muscle strengthening, mainly of the musculature surrounding the joints. After this period, the practice of physical exercises that considerably increase the energetic expenditure and require greater load intensity, can be gradually inserted into a training program for obese individuals [7].

Independent of the metabolic benefits promoted by the practice of physical exercises, it is known that the interruption of a program, can reduce or interrupt the physiological gains obtained $[8,9]$. Given this outlook and that the disease has a chronic pathophysiology character [1,2], motivation strategies and encouragement for daily adherence to exercise, should override the thoughts turned only to the selection or implementation modalities of exercises that will promote greater energy expenditure or faster weight loss results.

Hence, adherence is a necessary condition for the maintenance of benefits. That is why it is recommended that obese individuals, who wish to start physical exercise programs, look for psychologists or psychiatrists, as well as exercise physiologists [4]. Thus, the probability of adherence to a training program is higher due to a better management of psychological aspects, which are linked to the adoption of healthy lifestyle and behavior change from professionals specialized in this area. Social pressure and body exposure in gyms, parks or in any exercise practice sites, could lead the obese people to feel ashamed and stop the program due to emotional aspects. For this situation, for example, psychologic cognitive behavior treatment can be introduced in the weight loss program. That psychological intervention for obese individuals that start exercise programs includes: The family support and awareness, self-esteem improvement, peer network and community domains to promote behavior change, minimize relapse, and support healthy long-term behavior maintenance $[4,10]$.

It is necessary that exercise physiologists understand the pathophysiological aspects of obesity can be prevented and combated by the positive adaptations caused by physical exercise. However, we need to remember that obesity is a multifactorial disease and it requires an interdisciplinary approach, and the professionals should consider the biological individuality during the prescription of exercise training and the plurality of aspects involved in the treatment.

Through this proposal, it is believed that the chances of adhesion and adherence to physical training programs by obese individuals could be increased, which would impact positively in lifestyle and behavioral changes and consequently chronic maintenance of a healthy regime. In contrast, no matter how good the program and periodization of the physical training is, the chances of success will be reduced if the participant does not feel motivated to maintain adherence to regular practice of physical exercise.

\section{Ethical Statement}

No funding was provided for the development of this manuscript. The authors declare that there are no conflicts of interest.

\section{References}

1. Paes ST, Marins JC, Andreazzi AE (2015) Metabolic effects of exercise on childhood obesity: a current view. Rev Paul Pediatr 33: 122-129.

2. Paes ST, Gonçalves CF, Terra MM, Fontoura TS, Guerra $\mathrm{MO}$, et al. (2015) Childhood obesity: a (re) programming disease? J Dev Orig Health Dis 26: 1-6.

3. Church T (2011) Exercise in obesity, metabolic syndrome, and diabetes. Prog Cardiovasc Dis 53: 412-418.

4. Evert $A B$, Riddell MC (2015) Lifestyle intervention: nutrition therapy and physical activity. Med Clin North Am 99: 69-85.

5. Garber CE, Blissmer B, Deschenes MR, Franklin BA, Lamonte MJ, et al. (2011) American College of Sports Medicine position stand. Quantity and quality of exercise for developing and maintaining cardiorespiratory, musculoskeletal, and neuromotor fitness in apparently healthy adults: guidance for prescribing exercise. Med Sci Sports Exerc 43: 1334-1359.

6. Sabharwal S, Root MZ (2012) Impact of obesity on orthopaedics. J Bone Joint Surg Am 94: 1045-1052.

7. Washburn RA, Lambourne K, Szabo AN, Herrmann SD, Honas JJ, et al. (2014) Does increased prescribed exercise alter non-exercise physical activity/energy expenditure in healthy adults? A systematic review. Clin Obes 4: 1-20. 
8. Mujika I, Padilla S (2000) Detraining: loss of training-induced physiological and performance adaptations. Part I: short term insufficient training stimulus. Sports Med 30: 79-87.

9. Mora-Rodriguez R, Ortega JF, Hamouti N, Fernandez-Elias VE, Cañete Garcia-Prieto J, et al. (2014) Time-course effects of aerobic interval training and detraining in patients with metabolic syndrome. Nutr Metab Cardiovasc Dis 24: 792-798.

10. Wilfley DE, Kolko RP, Kass AE (2011) Cognitive-behavioral therapy for weight management and eating disorders in children and adolescents. Child Adolesc Psychiatr Clin N Am 20: 271-285. 